\title{
Induction of intestinal pro-inflammatory immune responses by lipoteichoic acid
}

\author{
Mojgan Zadeh ${ }^{1}$, Mohammad W Khan², Yong Jun Goh ${ }^{3}$, Kurt Selle ${ }^{3}$, Jennifer L Owen ${ }^{1}$, Todd Klaenhammer ${ }^{3}$ and \\ Mansour Mohamadzadeh ${ }^{1 *}$
}

\begin{abstract}
Background: The cellular and molecular mechanisms of inflammatory bowel disease are not fully understood; however, data indicate that uncontrolled chronic inflammation induced by bacterial gene products, including lipoteichoic acid (LTA), may trigger colonic inflammation resulting in disease pathogenesis. LTA is a constituent glycolipid of Gram-positive bacteria that shares many inflammatory properties with lipopolysaccharide and plays a critical role in the pathogenesis of severe inflammatory responses via Toll-like receptor 2 . Accordingly, we elucidate the role of LTA in immune stimulation and induced colitis in vivo.
\end{abstract}

Methods: To better understand the molecular mechanisms utilized by the intestinal microbiota and their gene products to induce or subvert inflammation, specifically the effect(s) of altered surface layer protein expression on the LTA-mediated pro-inflammatory response, the Lactobacillus acidophilus surface layer protein (SIp) genes encoding SlpB and SlpX were deleted resulting in a SlpB- and SlpX- mutant that continued to express SIpA (assigned as NCK2031).

Results: Our data show profound activation of dendritic cells by NCK2031, wild-type L. acidophilus (NCK56), and purified Staphylococcus aureus-LTA. In contrary to the LTA-deficient strain NCK2025, the LTA-expressing strains NCK2031 and NCK56, as well as S. aureus-LTA, induce pro-inflammatory innate and T cell immune responses in vivo. Additionally, neither NCK2031 nor S. aureus-LTA supplemented in drinking water protected mice from DSS-colitis, but instead, induced significant intestinal inflammation resulting in severe colitis and tissue destruction.

Conclusions: These findings suggest that directed alteration of two of the L. acidophilus NCFM-Slps did not ameliorate LTA-induced pro-inflammatory signals and subsequent colitis.

Keywords: Dendritic cells, Dextran sulfate sodium, Inflammatory bowel disease, Lipoteichoic acid, Toll-like receptor 2

\section{Background}

The intestinal immune system must co-exist with resident commensal microorganisms while maintaining the ability to defend against potential microbial challenge. This immune tolerance is a highly regulated process comprised of a myriad of biological checkpoints necessary to maintain homeostasis between the host and the gut microbiota [1]. In instances of inflammatory bowel disease (IBD), this tolerance between immune cells and intestinal bacteria is disrupted; however, causes of this

\footnotetext{
* Correspondence: m.zadeh@ufl.edu

1Department of Infectious Diseases and Pathology, Emerging Pathogens Institute, and Cancer Genetic Institute, University of Florida, Gainesville, FL, USA

Full list of author information is available at the end of the article
}

tolerance breakdown have not yet been determined $[2,3]$. Although the etiology of IBD is still unknown, exaggerated inflammation induced by activated innate immune cells via their interaction with the microbiota and their gene products, as well as infiltrating $\mathrm{CD} 4^{+}$ IFN $\gamma^{+} \mathrm{T}$ cells, likely play key roles in uncontrolled inflammation and tissue destruction [4-6]. Foxp $3^{+}$regulatory $\mathrm{T}$ cells (Tregs) also critically control intestinal inflammation [7] and significantly prevent colitis [8], suggesting a pivotal role for Tregs in intestinal immune homeostasis [9].

A fundamental challenge in preventing an imbalanced immune response is the understanding of how the host immune system distinguishes a pathogen from normal intestinal flora. One of the commensal microorganisms
C Biomed Central

(c) 2012 Zadeh et al; licensee BioMed Central Ltd. This is an Open Access article distributed under the terms of the Creative Commons Attribution License (http://creativecommons.org/licenses/by/2.0), which permits unrestricted use, distribution, and reproduction in any medium, provided the original work is properly cited. 
of the gut is L. acidophilus, which expresses unique surface layer proteins (Slps), including A, B, X, and abundant lipoteichoic acid (LTA). LTA is a zwitterionic glycolipid found in the cell wall of several Gram-positive bacterial strains, including L. acidophilus, which facilitates the adhesion, colonization, and invasion of cells by the bacteria [10,11]. The best studied form of LTA is composed of a polyglycerophosphate chain that is tethered to the membrane via a glycolipid anchor [12]. Studies indicate that LTA shares many of the inflammatory properties of lipopolysaccharide (LPS) via interactions with Toll-like receptors (TLRs) [13-16] which evoke diverse responses in innate cells through distinct signaling cascades [17].

Previously, we have demonstrated that deletion of the gene responsible for LTA biosynthesis in L. acidophilus NCFM diminishes this bacterium's capacity to stimulate the immune system; thereby suppressing pathogenic $\mathrm{CD} 4{ }^{+} \mathrm{T}$ cells in induced colitis $[18,19]$. To further investigate the role of LTA in inflammation, we engineered the NCK2031 strain in order to evaluate the effects, if any, of altered surface layer protein (Slp) expression on LTA-induced pro-inflammatory signals and colitis.

\section{Methods}

Materials Six to 8-week-old C57BL/6 were purchased from Jackson Laboratories (Bar Harbor, ME). Mice were maintained in microisolator cages under specific pathogen-free, Helicobacter-free conditions. Experiments were performed in an accredited establishment according to $\mathrm{NIH}$ guidelines in the Guide for Care and Use of Laboratory Animals (NIH-72-23), and animal protocols were approved by the local ethics committee. Dextran Sulfate Sodium (DSS) was obtained from MP Biochemicals (Solon, OH). Monoclonal antibodies for CD4, CD25, CD3, CD11c, CD11b, CD40, CD44, CD80, CD83, CD86, CD103, IL-10, IL-12, IFN $\gamma$, TNF $\alpha$, HLA-ABC (R\&D systems, Minneapolis, $\mathrm{MN}$ ) and (BD, Franklin Lakes, NJ), CD1a (Dako, Carpentaria, CA), mouse and human GM-CSF and IL-4 were purchased from Invitrogen (Carlsbad, CA).

Generation of NCK2031 To generate an L. acidophilus NCFM isogenic mutant defective in all three slp genes $(\operatorname{slp} A, \operatorname{slp} B$, and $\operatorname{slp} X)$, the $\operatorname{slp} B(\mathrm{LBA} 0175)$ and $\operatorname{slp} X$ (LBA0512) genes were sequentially deleted in an NCFM $\Delta u p p$ background host (NCK1909) using the upp-based counterselective gene replacement system [20]. Subsequently, attempts to insertionally inactivate the $\operatorname{slp} A$ gene (LBA0169) were made within the $\Delta \operatorname{slpBX}$ double mutant (NCK2030) using a pORI-based gene knockout system [21]. The resulting $\triangle \operatorname{slp} B X$ strain was deficient in SlpB and SlpX, but due to genetic instability of the insertion vector, NCK2031 continued to express SlpA (data not shown). Subsequently, wild-type $L$. acidophilus (NCK56), NCK2031, or LTA-deficient NCK2025 were propagated in de Man, Rogosa, and Sharpe broth (MRS, Difco) at $37^{\circ} \mathrm{C}$ for 15 hrs. The concentration of each $L$ acidophilus strain was adjusted to $1 \times 10^{9} \mathrm{CFU} / \mathrm{ml}$ based on OD600 readings that had previously been correlated with CFU numbers [22]. Each mouse was orally treated with $5 \times 10^{8} \mathrm{CFU}$ bacterial strain; therefore $500 \mu \mathrm{l}$ of $1 \times 10^{9} \mathrm{CFU} / \mathrm{ml}$ suspension was centrifuged, pelleted and then resuspended in 100 $\mu \mathrm{l}$ of PBS. Each mouse was then treated with $100 \mu \mathrm{l}$ PBS (control group) or $5 \times 10^{8} \mathrm{CFU}$ (of either L. acidophilus strain) orally in $100 \mu \mathrm{l}$ sterile PBS. Fecal pellets were collected from before, during, and for up to 8 days after $L$. acidophilus oral treatments. Each fecal pellet was resuspended in PBS (1:10 dilution, w/v). The suspension was then serially diluted and plated onto MRS agar containing Em $(2 \mu \mathrm{g} / \mathrm{mL})$. The homogenized material was serially diluted and plated onto MRS agar containing Em $(2 \mu \mathrm{g} / \mathrm{mL})$. The daily average CFU of the $L$. acidophilus strains in mouse feces were determined. For in vitro stimulation, bone marrow or human monocyte derived DCs were stimulated at a 1:1, 1:10, 1:100 ratio with live NCK2031, NCK56, NCK2025, or S. aureusLTA. Subsequently the ratio of 1:1 was chosen, as this did not overwhelmingly activate DCs and therefore did not result in cell anergy or apoptosis. For the oral gavage of mice, each mouse received $5 \times 10^{8} \mathrm{CFU}$ of NCK2031, NCK56, or NCK2025 in $100 \mu \mathrm{L}$ of PBS.

Cell culture Immature human $[22,23]$ or murine DCs [24] were treated with live L. acidophilus strains cells at 1:1 or with $S$. aureus-LTA $(50 \mu \mathrm{g} / \mathrm{mL})$ for $24 \mathrm{hrs}$. $L$. acidophilus- or S. aureus-LTA treated and untreated DCs $\left(5 \times 10^{5}\right)$ were then stained and analyzed by BD FACSCaliber or a multicolor FACSCanto. Cell supernatants were also collected and analyzed using cytometric bead array kits (BD Biosciences). At least $1 \times 10^{4}$ gated events per condition were acquired. Analysis software (BD CellQuest) allowed for calculation of cytokine values in supernatants at $\mathrm{pg} / \mathrm{mL}$.

Immunofluorescence The colons of mice $(n=5 /$ group) treated with live NCK2031, NCK56, NCK2025, S. aureus-LTA, or PBS alone were fillet-opened, rolled, and snap frozen at $-80^{\circ} \mathrm{C}$ in Tissue-Tek O.C.T. (Sakura Finetek USA, Inc., Torrance, CA). Sections $(5 \mu \mathrm{m})$ were cut, fixed in ice-cold methanol $\left(-20^{\circ} \mathrm{C}\right)$ for $15 \mathrm{~min}$ and blocked with $1 \%$ BSA. Sections were then incubated overnight at $4{ }^{\circ} \mathrm{C}$ with purified hamster anti-mouse CD11c (BD Biosciences) and rat anti-mouse IL-10 (BioLegend), and antibodies for IL-12, IFN $\gamma$, TNF $\alpha$, CD8, and Foxp3, followed by washing twice with PBS and incubation with anti-hamster AlexaFluor 594 and antirat AlexaFluor 488 (Invitrogen) for $1 \mathrm{hr}$. Sections were then washed twice with PBS and incubated for $10 \mathrm{~min}$ utes with 4,6-diamidino-2-phenylindole dihydrochloride 
(DAPI, Invitrogen), washed with PBS two times and mounted with anti-fade mounting medium, as described previously [25]. Images were acquired using TissueGnostics Tissue/Cell High Throughput Imaging and Analysis System and analyzed using ImageJ software.

Flow cytometry Groups of mice (5 mice/group) were inoculated orally with NCK2031, NCK56, NCK2025, or S. aureus-LTA $\left(5 \times 10^{8} \mathrm{CFU} / 100 \mu \mathrm{L}\right.$ of sterile PBS/ mouse) or PBS alone. Mice were then sacrificed after 1 , 3 , or 7 days; single cells were isolated from the colons [18], MLNs, and spleens and stained with CD11c, CD11b, CD103, MHC II, CD40, CD80, CD86, F4/80, CD4, CD3, CD80, or CD44 [26]. Stained cells were then fixed, permeabilized, and stained with IL-12, TNF $\alpha$, IFN $\gamma$ or isotype antibodies. At least $1 \times 10^{5}$ gated events per condition were acquired. Data were acquired with BD FACSCanto II and analyzed using Tree Star FlowJo software.

DSS-Induced Murine Colitis Groups of C57BL/6 mice ( $\mathrm{n}=5$ /group) were inoculated orally with NCK2031, NCK56, NCK2025, or $\left(5 \times 10^{8} \mathrm{CFU} / 100 \mu \mathrm{L} \mathrm{PBS} /\right.$ mouse) for four consecutive days. In addition, a group of mice was treated with purified S. aureus-LTA $(12.5$ $\mu \mathrm{g} / \mu \mathrm{L})$ [27] for 5 days. All of these mice received one 5 day cycle of $3 \%$ DSS in drinking water, followed by 3 days of regular drinking water, with or without $S$. aureus-LTA, and then sacrificed on day 13. Acute colitis was observed after the first cycle of DSS in the noninoculated group. Disease progression, including weight loss, diarrhea and fecal hemoccult blood positivity (FOB), was monitored throughout the study. Thereafter, mice were sacrificed and excised colon cross-sectional Swiss rolls were fixed in $10 \%$ formaldehyde and embedded in paraffin. Tissue sections $(4 \mu \mathrm{m})$ were stained with hematoyxylin and eosin (H\&E), and blindly scored, as described previously [28,29]. The grading, based on a scale from 0 to 28 , takes into account the degree of inflammatory infiltrate, the presence of erosion, ulceration, or necrosis, and the depth and surface extension of the lesion.

\section{Results}

\section{Immune stimulation by NCK2031}

To further characterize the role of LTA expression in inflammation, we attempted to generate surface layer protein (Slp)-deficient strains using the upp-counterselective gene replacement system [20]. The resulting strain, NCK2031, showed no detectable expression of SlpB or SlpX while retaining LTA expression. Attempted insertional mutation in the $\operatorname{slp} A$ gene was unstable and spontaneous $\mathrm{SlpA}^{+}$revertants occurred in the population. Therefore, the phenotype of this mutant was defined as $\mathrm{SlpA}^{+} \mathrm{B}^{-} \mathrm{X}^{-} \mathrm{LTA}^{+}$. SDS-PAGE analyses confirmed the expression of SlpA only (at $46 \mathrm{kDa}$ ), and the absence of SlpB and SlpX within the NCK2031 culture (data not shown). To evaluate any in vivo physiological effects of NCK2031 and its colonization in the gut of bacteria treated mice, the persistence of erythromycinresistant $\left(\mathrm{Em}^{\mathrm{r}}\right)$ NCK56 and $\mathrm{Em}^{\mathrm{r}}$ NCK2031 strains in the colon were determined in C57BL/6 mice orally treated once with $5 \times 10^{8} \mathrm{CFU} / \mathrm{mouse}$. Fecal pellets were collected the day before treatment and every day for up to 8 days after bacterial ingestion. Data reveal that mice cleared both NCK2031 and NCK56 (wild type) after 3 days, with significantly less NCK2031 excreted on days 2 and 3 (Figure 1a). Therefore, while the trends for clearance of the orally fed bacteria were similar, deletion of the SlpB and SlpX proteins appeared to accentuate clearance of the bacterium from the GI tract by one day, in vivo. Determining the time of bacterial clearance from the gut was essential to delineate the sampling time points used in the immunological studies.

To elucidate the physiological role of NCK2031 in dendritic cell (DC) activation, we co-cultured human monocyte derived DCs with NCK2031, NCK56, NCK2025, or purified S. aureus-LTA. Data revealed that the parent strain $\mathrm{NCK} 56$, the $\operatorname{SlpA}^{+} \mathrm{B}^{-} \mathrm{X}^{-} \mathrm{LTA}^{+}$strain NCK2031, and $S$. aureus-LTA profoundly stimulated human DCs, while the SlpA ${ }^{+} \mathrm{B}^{+} \mathrm{X}^{+} \mathrm{LTA}^{-}$strain NCK2025 only marginally modified $\mathrm{DC}$ function (Figure $1 \mathrm{~b}, \mathrm{c}$ ). Additionally, murine bone marrow derived DCs co-cultured with NCK2031 exhibited an up-regulation of MHC II, CD80, CD86, CD40, and increased production of intracellular interleukin (IL)-12 and TNF $\alpha$ when compared to DCs cultured with NCK56, NCK2025 or S. aureus-LTA (Figure 1d). These data indicate that LTA is not playing a regulatory role as seen in other studies $[27,30]$, but rather, functions as a highly pro-inflammatory molecule when expressed on L. acidophilus [19].

\section{Activation of DCs, macrophages, and T cells by NCK2031}

To overcome the undesired effects of cell death induced by enzymatic reagents (i.e. collagenase) necessary for cell isolation we employed TissueGnostics fluorescent microscopy [18] and confocal microscopy (Figure 2a, 3a) to analyze the cell populations and their cytokine expression in the colons of bacteria treated mice. As demonstrated previously, a significantly higher percentage of CD $11 \mathrm{c}^{+} \mathrm{IL}-10^{+} \mathrm{DCs}$ per total $\mathrm{DAPI}^{+}$cells were observed in the colons of mice treated with NCK2025 when compared to mice treated with NCK2031, NCK56, or S. aureus-LTA on days 1 and 3 , but not by day 7 (data not shown). In contrast, IL-12 and TNF $\alpha$ production by colonic DCs was significantly higher in mice treated with NCK2031, NCK56, or S. aureus-LTA when compared to mice that were treated with NCK2025 or PBS (Figure 2b). To expand upon these findings, we studied the ability of the LTA-expressing strains to induce 


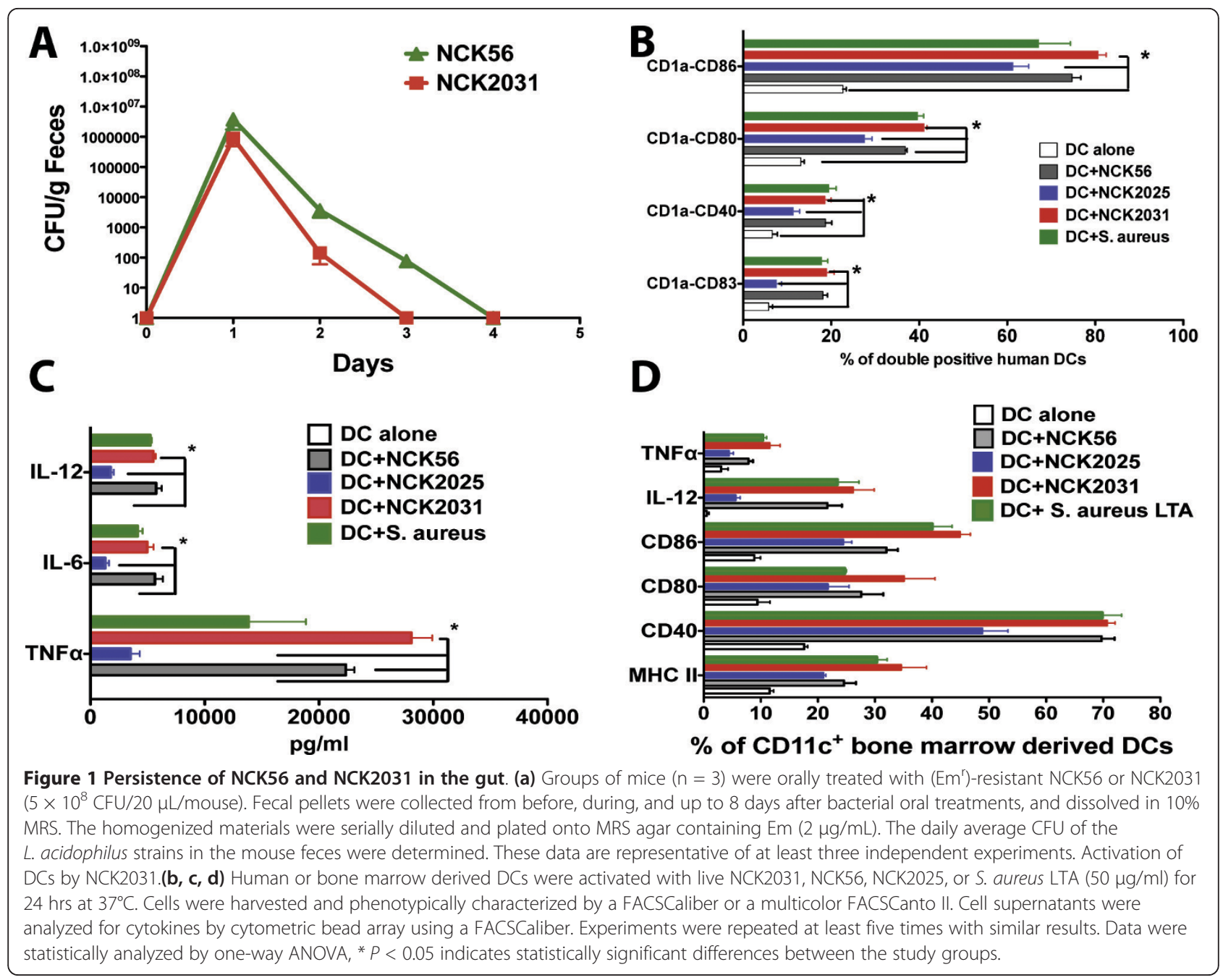

the stimulation of DCs, macrophages, $\mathrm{CD} 4^{+}$and $\mathrm{CD} 8^{+}$ $\mathrm{T}$ cells in vivo. While no significant differences were seen in the expression of MHC II, CD40, CD80, or

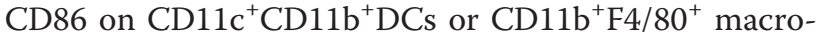
phages (data not shown), cytoplasmic IL-12 and TNF $\alpha$ were significantly increased in $\mathrm{CD} 11 \mathrm{c}^{+} \mathrm{MHC} \mathrm{II}{ }^{+} \mathrm{DCs}$ derived from the colons (Figure 2c), and mesenteric lymph nodes (MLNs) (Figure 3a), but not the spleens of mice that were treated with NCK2031, NCK56, or $S$. aureus -LTA versus PBS or NCK2025 (Figure 3b).

Recent studies have indicated that there is a significant recruitment of colonic $\mathrm{F} 4 / 80^{+}$macrophages in IBD compared to that seen in normal mucosa [31]. Thus, we investigated the impact of the genetically modified strains versus the wild type NCK56 and $S$. aureus-LTA on the recruitment and activation of colonic $\mathrm{F} 4 / 80^{+}$ macrophages in vivo. Based on data generated by TissueGnostics, it was apparent that NCK2031, NCK56, and $S$. aureus-LTA significantly induced colonic $\mathrm{F} 4 / 80^{+}$ macrophages to produce IL-12 and TNFa; the expression of these cytokines was low in NCK2025treated mice after $24 \mathrm{hrs}$ (Figure $4 \mathrm{a}, \mathrm{b}$ ), but had leveled off by days 3 and 7 (data not shown). In contrast, IL-10 was highly expressed in NCK2031, NCK56, NCK2025, and $S$. aureus-LTA treated mice compared to untreated mice (Figure $4 \mathrm{c}$ ). This observation may reflect the nature of the bacteria and their gene products, which can differentially stimulate these colonic cells to become either pro-inflammatory or regulatory. These data suggest that activation of intestinal cells and induction of inflammation may be triggered by the presence of LTA, as previously shown in lungs with airway inflammation [32,33].

In addition, colonic $\mathrm{CD} 4^{+} \mathrm{T}$ cells from mice treated with NCK2031, NCK56, or S. aureus-LTA expressed higher levels of IFN $\gamma$ compared to mice treated with NCK2025 or PBS (Figure 5a). Treatment of mice with NCK2031, NCK56, and S. aureus-LTA also induced significantly increased expression of IFN $\gamma$ and TNF $\alpha$ (Figure $5 \mathrm{~b}$ ), but not IL-17 (data not shown), in the $\mathrm{CD}^{+} \mathrm{T}$ 


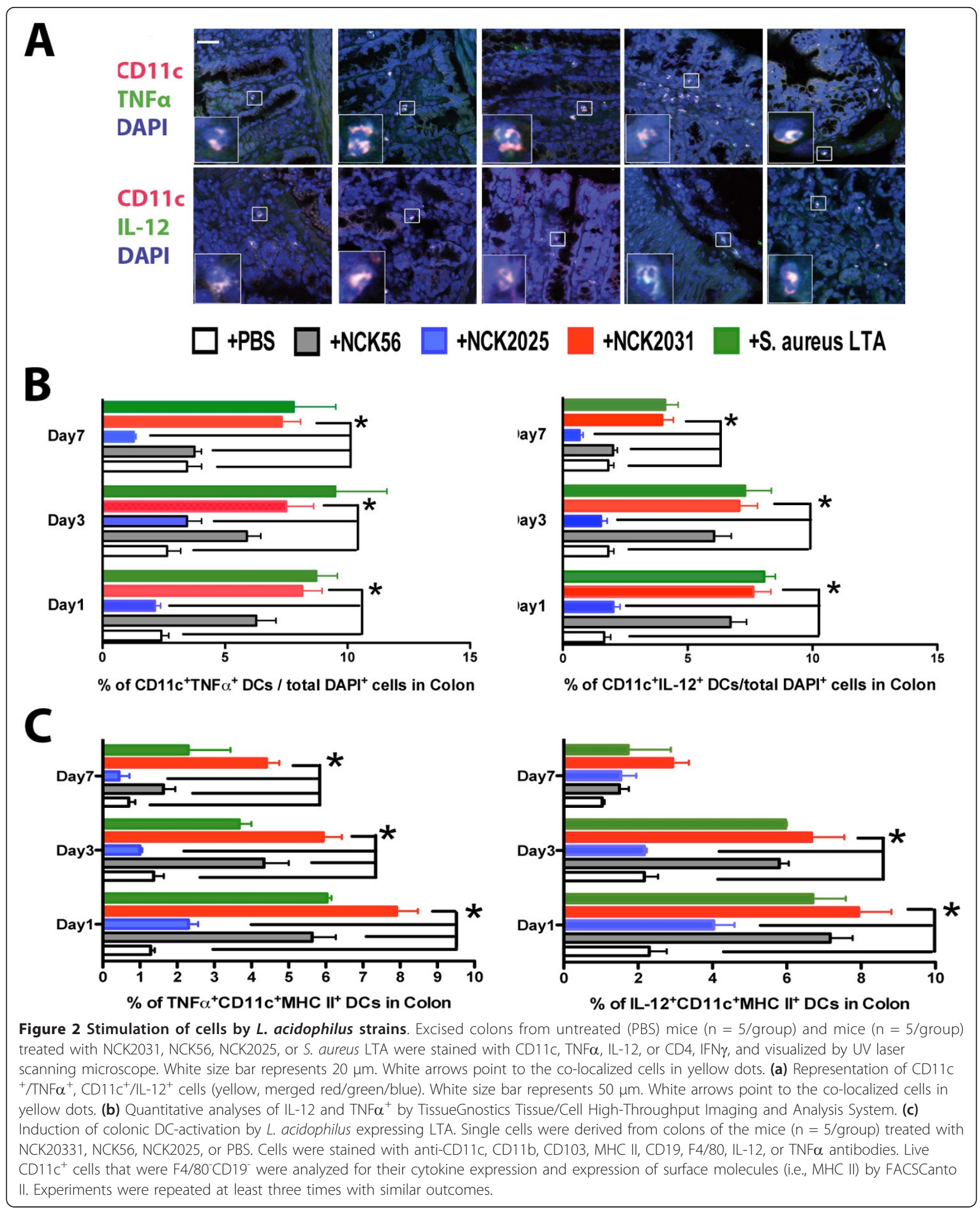




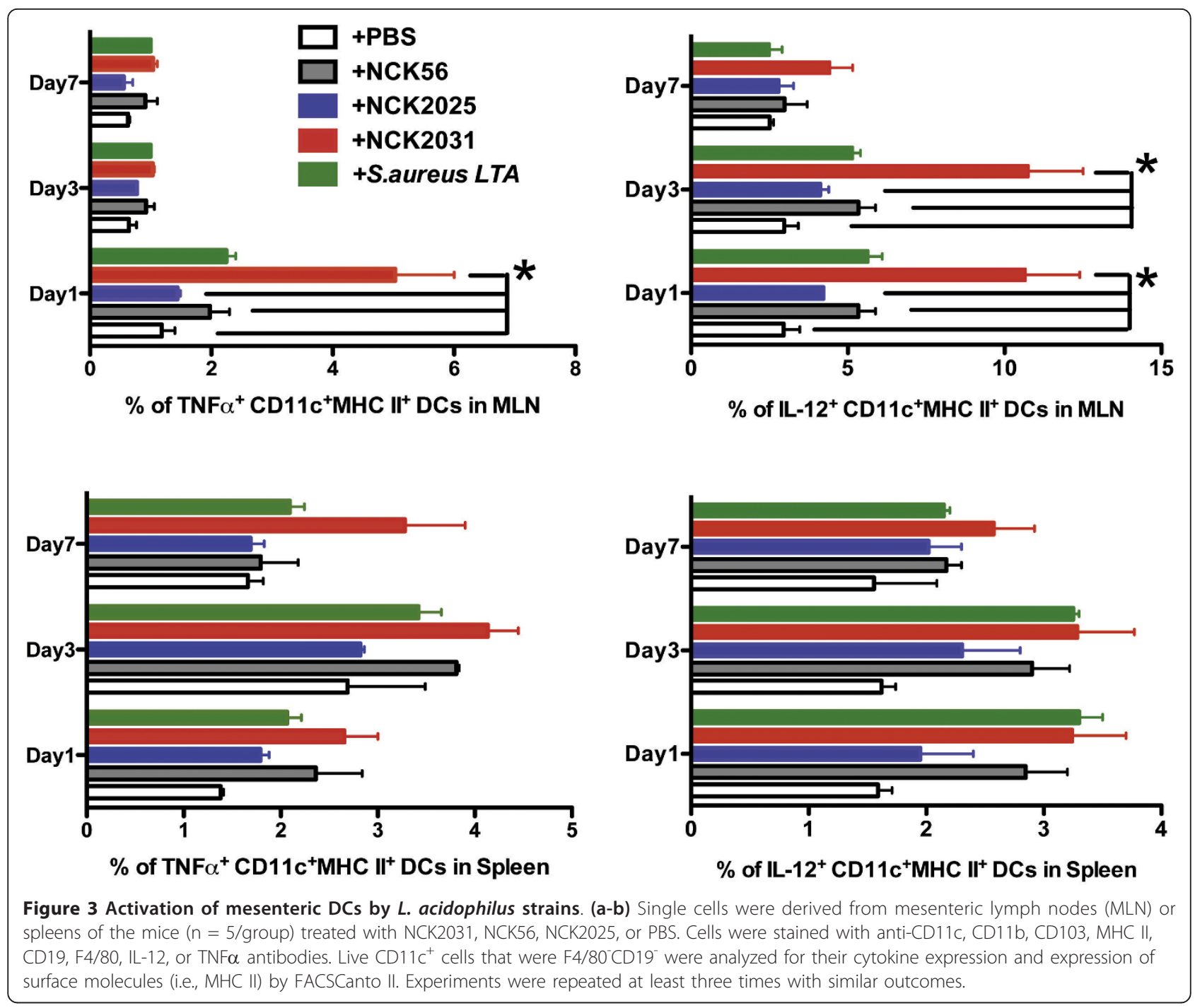

cells from the MLNs; a significant trend was not seen in the spleen (data not shown). The $\mathrm{CD}^{+}$cells seemed to be less affected in the NCK2025-treated mice (Figure 5b).

It has recently been demonstrated that $\mathrm{CD} 8^{+} \mathrm{T}$ cells efficiently prevent the generation of colitis [34,35] and play a critical role in controlling potentially pathogenic $\mathrm{T}$ cells [36] in IBD patients $[37,38]$. Such $\mathrm{CD}^{+} \mathrm{T}$ cells with regulatory activity reside in the lamina propria (LP) of healthy individuals but not in the LP of patients with IBD $[37,38]$. Interestingly, the percentages of CD8 ${ }^{+} \mathrm{T}$ cells in the colons of mice treated with NCK2031, NCK56, or S. aureus-LTA were significantly reduced (data not shown) when compared to NCK2025 treated mice. The majority of $\mathrm{CD}^{+} \mathrm{T}$ cells in the colonic tissues from all groups of mice were IFN $\gamma$ negative (data not shown), suggesting that colonic $\mathrm{CD}^{+} \mathrm{T}$ cells are probably not involved in immune stimulation; rather, they exert immune regulation in the colon [36]. To demonstrate whether resident or recruited colonic $\mathrm{CD} 8^{+} \mathrm{T}$ cells are Foxp $3^{+}$, these cells were visualized by TissueGnostics fluorescent microscopy. Surprisingly, there were no significant differences in Foxp $3^{+}$expression between the groups of the mice that were treated with the various L. acidophilus strains or S. aureus-LTA (data not shown). Further studies are required to study this cell type in colitis disease models. The activity of $\mathrm{CD} 8^{+} \mathrm{T}$ cells within the MLN and spleen was also analyzed. NCK2031, NCK56, and S. aureus-LTA significantly stimulated MLN $\mathrm{CD} 8^{+} \mathrm{CD} 44^{\text {high }} \mathrm{T}$ cells to produce IFN $\gamma$ on day 3 and TNF $\alpha$ on day 7 (Figure 5c); no significant differences in the production of these cytokines were seen in the splenic $\mathrm{CD}^{+} \mathrm{T}$ cells (data not shown). Collectively, these data indicate that the LTA-expressing strains, NCK2031 and NCK56, activate DCs and macrophages in a pro- 


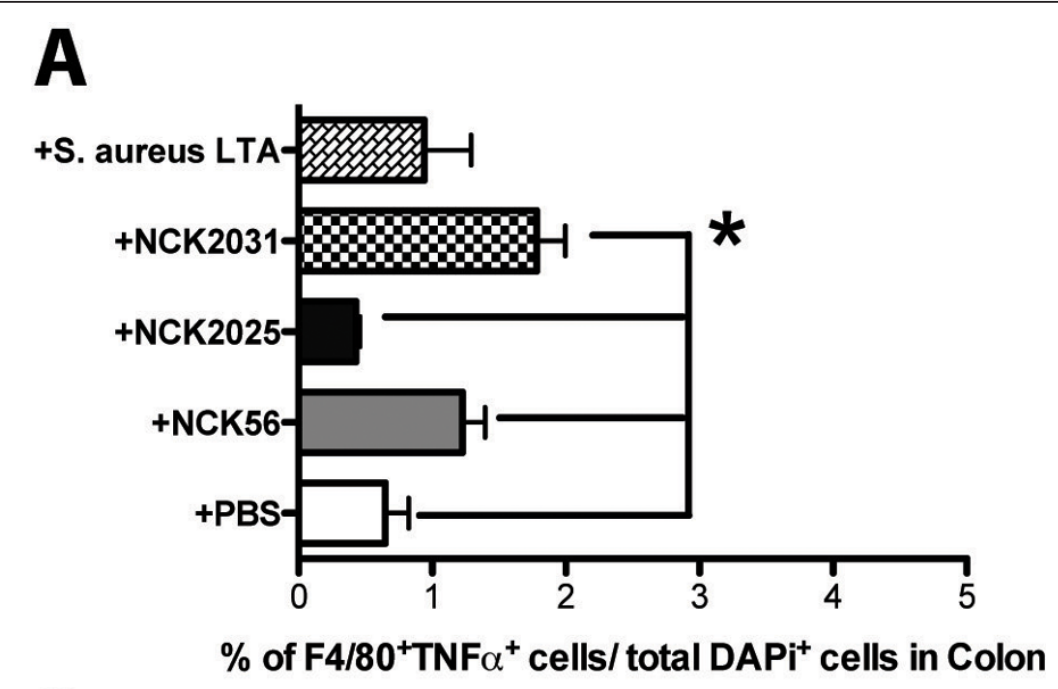

B

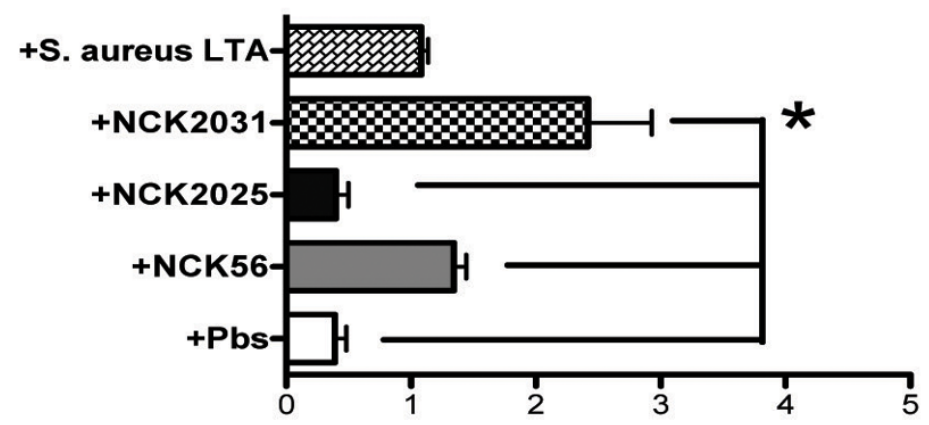

$\%$ of $\mathrm{FH} \mathbf{8 0}^{+} \mathrm{IL}^{-12}{ }^{+}$cells/total $\mathrm{DAPI}^{+}$cells in Colon
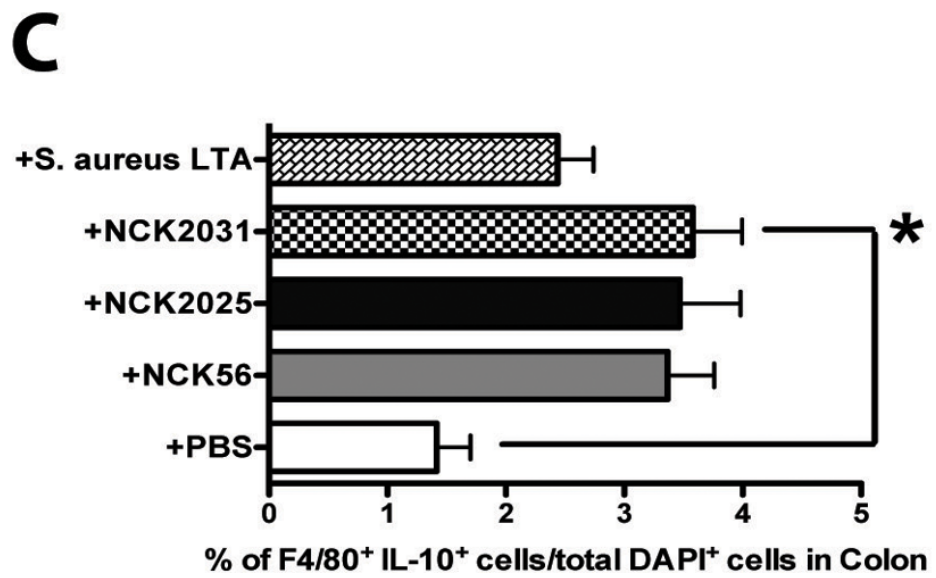

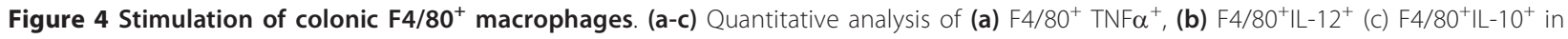
untreated (PBS) mice and in mice treated with NCK2031, NCK56, NCK2025, and S. aureus-LTA. Data were statistically analyzed by one-way ANOVA, ${ }^{*} P<0.05$ indicates significance of the data between the study groups. 


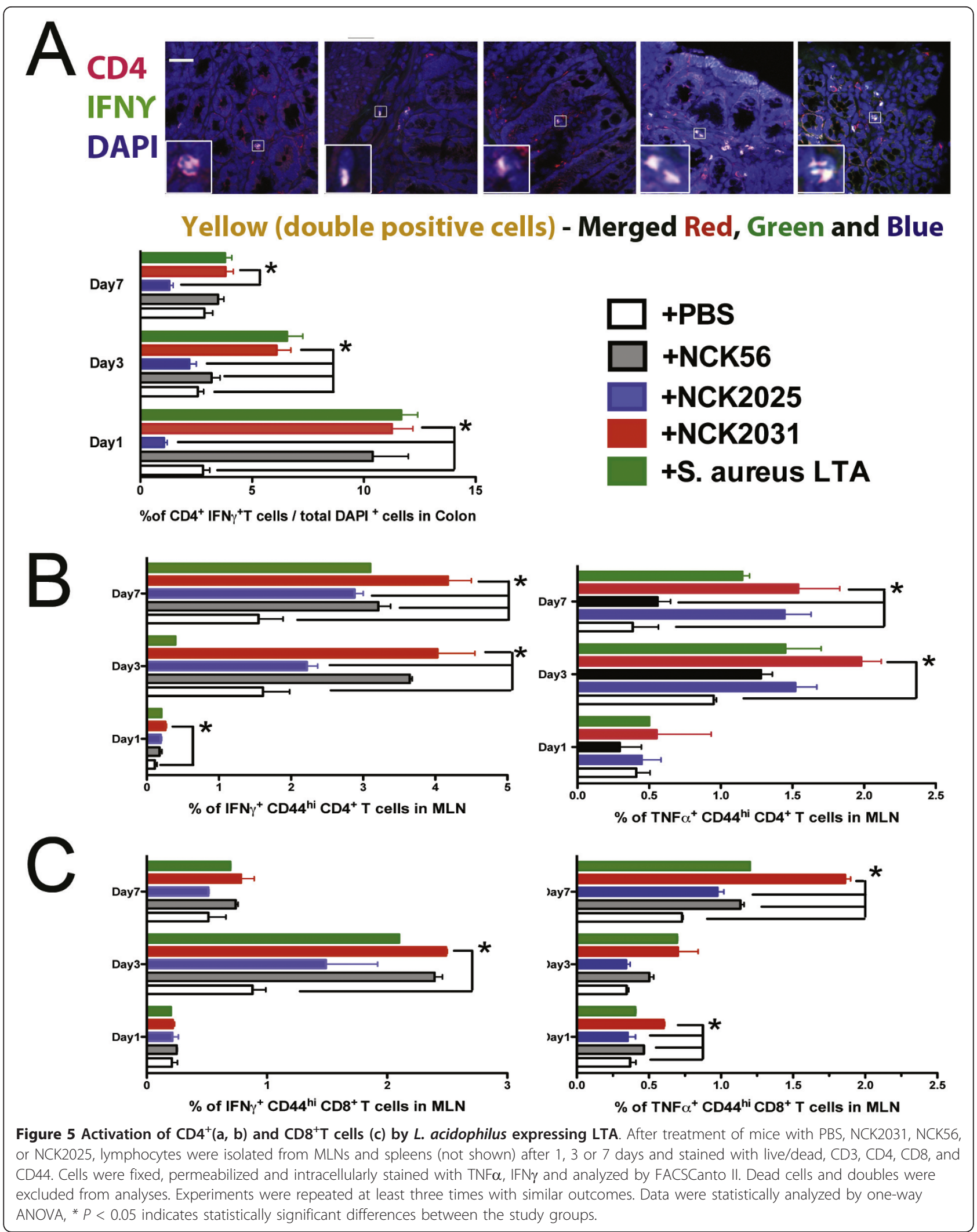


inflammatory manner, which in turn, may directly elicit $\mathrm{CD} 4^{+}$and $\mathrm{CD} 8^{+} \mathrm{T}$ cell activation.

Exacerbation of DSS-induced murine colitis by NCK2031 and S. aureus-LTA

To more thoroughly investigate the pro-inflammatory mechanisms induced by LTA, we utilized the DSSmouse model for colitis [18]. Data show that DSS generated murine colitis in PBS-treated mice (Figure 6ad). Mice began to lose weight after day 8 and developed severe diarrhea at days 10-13 (Figure 6b, c). To specifically address the role of LTA expression by NCK2031, mice were treated with NCK2031, NCK56, NCK2025 or S. aureus-LTA dissolved in drinking water. NCK2031, NCK56, or soluble $S$. aureus-LTA did not prevent the onset of colitis and the mice developed colitis similarly

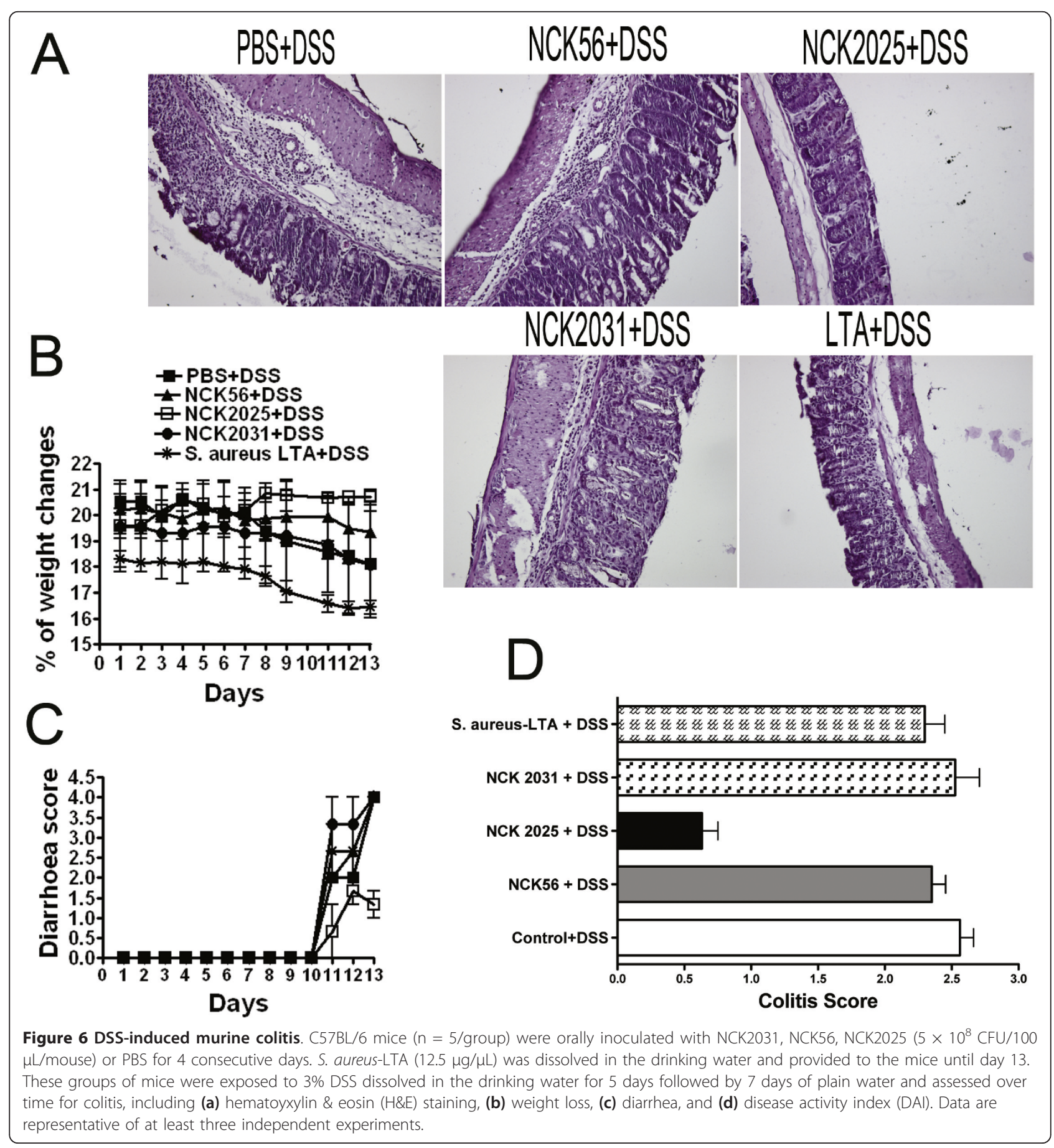


to non-treated mice (Figure 6a-d). In contrast, treatment with NCK2025 significantly prevented weight loss and reduced diarrhea (Figure 6), as previously documented [18]. Overall, the "Disease Activity Index" (DAI) was significantly increased for untreated animals and mice treated with NCK2031, NCK56, and S. aureus-LTA (Figure $6 \mathrm{~d}$ ). The colons from these mice exhibited ulcerated epithelium with significant inflammation confined to the mucosa, while colonic tissue obtained from mice treated with NCK2025 did not exhibit evidence of significant inflammation (Figure 6a).

\section{Discussion}

Excessive stimulation of intestinal innate cells, including DCs, with commensal bacteria and/or their gene products results in immune dysfunction that can generate uncontrolled inflammation leading to tissue destruction and colitis [39]. Precise cellular and molecular mechanisms of these induced inflammatory immune responses in IBD remain poorly understood. Data so far indicate that chronic intestinal inflammation coincides with elevated levels of pro-inflammatory cytokines (i.e., IL-12, $\mathrm{TNF} \alpha$ ) [40], and the differentiation/activation of pro-inflammatory DC-subsets and pathogenic $\mathrm{CD} 4^{+} \mathrm{T}$ cells [41]. Accordingly, promising studies show that inhibition of detrimental signals induced by stimulatory bacterial products mitigates IBD progression [42-49].

Together, our data show that LTA plays a critical role in the induction of the inflammatory responses and cannot prevent mice from developing colitis. Contrary to our findings, other studies have shown that lactobacilliLTA induces regulatory signals (i.e., IL-10) via Erk1/2 signaling, resulting in anti-inflammatory mechanisms [30]. Other reports also indicate that commensal LTA protects mice from DSS-induced colitis and ameliorates impaired epithelial tight junctions [27,50]. This discrepancy may lay in the methodological approaches and reagents that were used in these studies. Here we demonstrate that LTA and LTA expressing bacteria posses the ability to stimulate innate immune component cells, including DCs and macrophages, which in turn, can trigger pathogenic IFN $\gamma$-secreting $\mathrm{CD}^{+} \mathrm{T}$ cells in disease progression.

The role of IFN $\gamma$ expressed in the colon is unclear, as it has been shown that this cytokine exerts protective features in different models of inflammation [51]. For example, in a murine model of multiple sclerosis, neutralization of IFN $\gamma$ resulted in inflammatory immune responses [52]. Similarly, in a mouse model of IBD, IFN $\gamma$ has been shown to suppress IL-23 [53], and collagen-induced arthritis is induced in the absence of IFN $\gamma$ signaling [54]. However, in the models we have previously used for experimental DSS inducing epithelial injury (i.e., leaky mucosa) resulting in colitis or pathogenic $\mathrm{CD} 4{ }^{+} \mathrm{CD} 45 \mathrm{RB}^{\text {high }} \mathrm{T}$ cell transfer; IFN $\gamma$ seems to be involved in the pathogenesis of the induced colitis. Additionally, IFN $\gamma$ contributes to intestinal pathology and lethality in lipopolysaccharide-sensitization models of toxic shock syndrome (TSS) $[55,56]$. Further studies are needed to clearly elucidate the role of this cytokine in colitis and the timing of its production during disease progression.

Our results show that in vitro and in vivo, NCK2031 expressing LTA and purified S. aureus-LTA induce intestinal immune activation resulting in the production of TNF $\alpha$ and IL-12 and the development of proinflammatory cells such as $\mathrm{CD} 11 \mathrm{c}^{+} \mathrm{TNF} \alpha^{+} \mathrm{IL}-12^{+} \mathrm{DCs}$ and $\mathrm{F} 4 / 80^{+}$macrophages that may contribute to an undesired $\mathrm{CD} 4^{+} \mathrm{IFN} \gamma^{+} \mathrm{TNF}^{+} \mathrm{T}$ cell pro-inflammatory response seen in colitis. Conversely, treatment with LTA-deficient NCK2025 elicited regulatory signals and induced less inflammation, as demonstrated here and previously $[18,19]$. We have previously demonstrated the involvement of SlpA of L. acidophilus NCFM in the immune regulation of DC functions [57]. Studies are underway to better delineate the physiological role of SlpA from this bacterium in vivo. Finally, an acute colitis characterized by bloody diarrhea, ulcerations and infiltrations with granulocytes can be induced in mice that are exposed for several days to significantly dissolved DSS polymers in drinking water $[58,59]$. As seen in Figure 6, we also could confirm such clinical signs when DSS was used to induce colitis. Additionally, our data clearly show not only the proinflammatory nature of LTA but also the significantly exacerbated disease progression in the colon of mice that received LTA in the drinking water. Thus, these data are in sharp contrast to the notion that LTA plays a regulatory role and possesses the ability to mitigate DSS-induced colitis, as described previously [27]. In summary, oral administration of DSS to mice induces an acute colitis, followed by a slow colonic regeneration of the epithelium with a concomitant exaggerated inflammation; furthermore, LTA did not reduce the levels DSS-induced colitis or promote the rapid healing of ulcerated and destroyed epithelial tissues in our studies.

\section{Conclusions}

Our data strongly suggest that directed alteration of two of the L. acidophilus-Slps did not ameliorate LTAinduced pro-inflammatory signals and subsequent colitis. Additionally, further studies are required to elucidate the role of L. acidophilus-Slps in the steady state of normal gut homeostasis and in diseases such as colitis and colon cancer where deregulated inflammation plays a critical role in disease progression. Finally, LTA did not mitigate DSS-induced colitis but induced further colonic inflammation. 


\section{Abbreviations}

DCs: Dendritic cells; LTA: Lipoteichoic acid; IL: Interleukin; TNFa: Tumor Necrosis Factor-alpha; Slps: Surface layer proteins; DAl: Disease Activity Index.

\section{Acknowledgements}

This work was supported in part by the by NIH Grant 1R01Al098833-01, Danisco USA, and the North Carolina Dairy Foundation. We also thank Dr. Praveen Bere, Dr. Mary Brown, and Robert Roman for their generous support and excellent technical assistant and discussion of this work.

\section{Author details}

'Department of Infectious Diseases and Pathology, Emerging Pathogens Institute, and Cancer Genetic Institute, University of Florida, Gainesville, FL, USA. ${ }^{2}$ Northwestern University, Feinberg School of Medicine, Chicago, IL, USA. ${ }^{3}$ Department of Food, Bioprocessing \& Nutrition Sciences, N.C. State University, Raleigh, NC, USA.

\section{Authors' contributions}

MZ and MWK carried out all animal work, immunocytochemistry (i.e., high throughput and confocal imaging) and flow cytometry experiments. Additionally, MZ and MWK gathered the raw data and using statistical analyses and graphic programs compiled the data into meaningful information. MZ, MWK, JLO also contributed to writing the Methods section of the manuscript. MZ and MWK collected all of the graphics and formed the figures of the Manuscript. YJG, TK designed experiments and contributed to writing the Methods section. KS performed SIp proteome analysis on NCK2031 strain. MM designed experiments, discussed and wrote the manuscript. All authors have read and approved this manuscript.

\section{Competing interests}

The authors declare that they have no competing interests.

Received: 28 November 2011 Accepted: 16 March 2012

Published: 16 March 2012

\section{References}

1. Weiner HL, da Cunha AP, Quintana F, Wu H: Oral tolerance. Immunol Rev 2011, 241(1):241-259.

2. Lee YK, Mazmanian SK: Has the microbiota played a critical role in the evolution of the adaptive immune system? Science 2010, 330:1768-1773.

3. Strober W, Fuss I, Mannon P: The fundamental basis of inflammatory bowel disease. J Clin Invest 2007, 117:514-521.

4. Powrie F: T cells in inflammatory bowel disease: protective and pathogenic roles. Immunity 1995, 3:171-174

5. Cheroutre H: In IBD eight can come before four. Gastroenterology 2006 , 131:667-670

6. Elson CO, Cong Y, McCracken VJ, Dimmitt RA, Lorenz RG, Weaver CT: Experimental models of inflammatory bowel disease reveal innate, adaptive, and regulatory mechanisms of host dialogue with the microbiota. Immunol Rev 2005, 206:260-276.

7. Coombes $\mathrm{JL}$, Robinson NJ, Maloy KJ, Uhlig HH, Powrie F: Regulatory T cells and intestinal homeostasis. Immunol Rev 2005, 204:184-194.

8. Read S, Malmstrom V, Powrie F: Cytotoxic T lymphocyte-associated antigen 4 plays an essential role in the function of $\operatorname{CD} 25(+) C D 4(+)$ regulatory cells that control intestinal inflammation. J Exp Med 2000, 192:295-302.

9. Fontenot JD, Gavin MA, Rudensky AY: Foxp3 programs the development and function of CD4 + CD25+ regulatory T cells. Nat Immunol 2003, 4:330-336.

10. Sutcliffe IC, Shaw N: Atypical lipoteichoic acids of gram-positive bacteria. J Bacteriol 1991, 173:7065-7069.

11. Alkan ML, Beachey EH: Excretion of lipoteichoic acid by group $A$ streptococci. Influence of penicillin on excretion and loss of ability to adhere to human oral mucosal cells. J Clin Invest 1978, 61:671-677.

12. Reichmann NT, Grundling A: Location, synthesis and function of glycolipids and polyglycerolphosphate lipoteichoic acid in Gram-positive bacteria of the phylum Firmicutes. FEMS MicrobiolLett 2011, 319:97-105.

13. Su SC, Hua KF, Lee H, Chao LK, Tan SK, Yang SF, et al: LTA and LPS mediated activation of protein kinases in the regulation of inflammatory cytokines expression in macrophages. ClinChimActa 2006, 374:106-115.
14. Zidek Z, Farghali H, Kmonickova E: Intrinsic nitric oxide-stimulatory activity of lipoteichoic acids from different Gram-positive bacteria. Nitric Oxide 2010, 23:300-310.

15. Chang HC, Lin KH, Tai YT, Chen JT, Chen RM: Lipoteichoic acid-induced TNF-alpha and IL-6 gene expressions and oxidative stress production in macrophages are suppressed by ketamine through downregulating Tolllike receptor 2-mediated activation of ERK1/2 and NFkappaB. Shock 2010, 33:485-492.

16. Kengatharan KM, De Kimpe S, Robson C, Foster SJ, Thiemermann C: Mechanism of gram-positive shock: identification of peptidoglycan and lipoteichoic acid moieties essential in the induction of nitric oxide synthase, shock, and multiple organ failure. J Exp Med 1998, 188:305-315.

17. Akira S, Uematsu S, Takeuchi O: Pathogen recognition and innate immunity. Cell 2006, 124:783-801.

18. Mohamadzadeh M, Pfeiler EA, Brown JB, Zadeh M, Gramarossa M, Managlia $\mathrm{E}_{\text {, et }}$ al: Regulation of induced colonic inflammation by Lactobacillus acidophilus deficient in lipoteichoic acid. Proc Nat/AcadSci USA 2011, 108:4623-4630.

19. Saber R, Zadeh M, Pakanati KC, Bere P, Klaenhammer T, Mohamadzadeh M: Lipoteichoic acid-deficient Lactobacillus acidophilus regulates downstream signals. Immunotherapy 2011, 3:337-347.

20. Goh YJ, Azcarate-Peril MA, O'Flaherty S, Durmaz E, Valence F, Jardin J, et al: Development and application of a upp-based counterselective gene replacement system for the study of the S-layer protein SlpX of Lactobacillus acidophilus NCFM. Appl Environ Microbiol 2009, 75:3093-3105.

21. Russell WM, Klaenhammer TR: Efficient system for directed integration into the Lactobacillus acidophilus and Lactobacillus gasseri chromosomes via homologous recombination. Appl Environ Microbiol 2001, 67:4361-4364.

22. Mohamadzadeh M, Berard F, Essert G, Chalouni C, Pulendran B, Davoust J, et al: Interleukin 15 skews monocyte differentiation into dendritic cells with features of Langerhans cells. J Exp Med 2001, 194:1013-1020.

23. Sallusto F, Lanzavecchia A: Efficient presentation of soluble antigen by cultured human dendritic cells is maintained by granulocyte/ macrophage colony-stimulating factor plus interleukin 4 and downregulated by tumor necrosis factor alpha. J Exp Med 1994, 179:1109-1118.

24. Pulendran B, Dillon S, Joseph C, Curiel T, Banchereau J, Mohamadzadeh M: Dendritic cells generated in the presence of GM-CSF plus IL-15 prime potent CD8+ Tc1 responses in vivo. Eur J Immunol 2004, 34:66-73.

25. Gounaris E, Tung CH, Restaino C, Maehr R, Kohler R, Joyce JA, et al: Live imaging of cysteine-cathepsin activity reveals dynamics of focal inflammation, angiogenesis, and polyp growth. PLoS One 2008, 3:e2916.

26. Mohamadzadeh M, Olson S, Kalina WW, Ruthel G, Demmin GL, Warfield KL, et al: Lactobacilli activate human dendritic cells that skew T cells toward T helper 1 polarization. Proc Nat/AcadSci USA 2005, 02(8):2880-2885.

27. Rakoff-Nahoum S, Paglino J, Eslami-Varzaneh F, Edberg S, Medzhitov R: Recognition of commensal microflora by toll-like receptors is required for intestinal homeostasis. Cell 2004, 118:229-241.

28. Cooper HS, Murthy SN, Shah RS, Sedergran DJ: Clinicopathologic study of dextran sulfate sodium experimental murine colitis. Lab Invest 1993, 69:238-249.

29. Murthy SN, Cooper HS, Shim H, Shah RS, Ibrahim SA, Sedergran DJ: Treatment of dextran sulfate sodium-induced murine colitis by intracoloniccyclosporin. Dig Dis Sci 1993, 38:1722-1734.

30. Kaji R, Kiyoshima-Shibata J, Nagaoka M, Nanno M, Shida K: Bacterial teichoic acids reverse predominant IL-12 production induced by certain lactobacillus strains into predominant IL-10 production via TLR2dependent ERK activation in macrophages. J Immunol 2010, 184:3505-3513

31. Lloyd CM, Phillips AR, Cooper GJ, Dunbar PR: Three-colour fluorescence immunohistochemistry reveals the diversity of cells staining for macrophage markers in murine spleen and liver. $J$ Immunol Methods 2008, 334:70-81.

32. Lee IT, Lee CW, Tung WH, Wang SW, Lin CC, Shu JC, et al: Cooperation of TLR2 with MyD88, PI3K, and Rac1 in lipoteichoic acid-induced CPLA2/ COX-2-dependent airway inflammatory responses. Am J Pathol 2010, 176:1671-1684.

33. Lee IT, Wang SW, Lee CW, Chang CC, Lin CC, Luo SF, et al: Lipoteichoic acid induces HO-1 expression via the TLR2/MyD88/c-Src/NADPH oxidase 
pathway and Nrf2 in human tracheal smooth muscle cells. J Immunol 2008, 181:5098-5110.

34. Menager-Marcq I, Pomie C, Romagnoli P, van Meerwijk JP: CD8 + CD28regulatory $\mathrm{T}$ lymphocytes prevent experimental inflammatory bowel disease in mice. Gastroenterology 2006, 131:1775-1785.

35. Ho J, Kurtz CC, Naganuma M, Ernst PB, Cominelli F, Rivera-Nieves J: A CD8 +/CD103high T cell subset regulates TNF-mediated chronic murine ileitis. J Immunol 2008, 180:2573-2580.

36. Fleissner D, Frede A, Knott M, Knuschke T, Geffers R, Hansen W, et al: Generation and function of immunosuppressive human and murine CD8 (+) T cells by transforming growth factor-beta and retinoic acid. Immunol 2011, 134:82-92

37. Allez M, Brimnes J, Dotan I, Mayer L: Expansion of CD8+ T cells with regulatory function after interaction with intestinal epithelial cells. Gastroenterology 2002, 123:1516-1526.

38. Brimnes J, Allez M, Dotan I, Shao L, Nakazawa A, Mayer L: Defects in CD8+ regulatory $T$ cells in the lamina propria of patients with inflammatory bowel disease. J Immunol 2005, 174:5814-5822.

39. Macdonald TT, Monteleone G: Immunity, inflammation, and allergy in the gut. Science 2005, 307:1920-1925.

40. Rutgeerts P, Vermeire S, Van Assche G: Biological therapies for inflammatory bowel diseases. Gastroenterology 2009, 136:1182-1197.

41. Strober W, Fuss IJ, Blumberg RS: The immunology of mucosal models of inflammation. Annu Rev Immunol 2002, 20:495-549.

42. Simpson SJ, Shah S, Comiskey M, de Jong YP, Wang B, Mizoguchi E, et al: T cell-mediated pathology in two models of experimental colitis depends predominantly on the interleukin 12/Signal transducer and activator of transcription (Stat)-4 pathway, but is not conditional on interferon gamma expression by T cells. J Exp Med 1998, 187:1225-1234.

43. Kullberg MC, Rothfuchs AG, Jankovic D, Caspar P, Wynn TA, Gorelick PL, et al: Helicobacter hepaticus-induced colitis in interleukin-10-deficient mice: cytokine requirements for the induction and maintenance of intestinal inflammation. Infect Immun 2001, 69:4232-4241.

44. Monteleone I, Sarra M, Del Vecchio Blanco G, Paoluzi OA, Franze E, Fina D, et al: Characterization of IL-17A-producing cells in celiac disease mucosa. J Immunol 2010, 184:2211-2218.

45. Pallone F, Fina D, Caruso R, Monteleone G: Role of IL-21 in inflammatory bowel disease. Expert Rev Clin/mmunol 2010, 6:537-541.

46. Sarra M, Monteleone G: Interleukin-21: a new mediator of inflammation in systemic lupus erythematosus. J Biomed Biotechnol 2010, 2010:294582.

47. Sarra M, Monteleone I, Stolfi C, Fantini MC, Sileri P, Sica G, et al: Interferongamma-expressing cells are a major source of interleukin-21 in inflammatory bowel diseases. Inflamm Bowel Dis 2010, 16:1332-1339.

48. Sarra M, Pallone F, Macdonald TT, Monteleone G: IL-23/IL-17 axis in IBD. Inflamm Bowel Dis 2010, 16:1808-1813.

49. Popivanova BK, Kitamura K, Wu Y, Kondo T, Kagaya T, Kaneko S, et al: Blocking TNF-alpha in mice reduces colorectal carcinogenesis associated with chronic colitis. J Clin Invest 2008, 118:560-570.

50. Miyauchi E, Morita H, Okuda J, Sashihara T, Shimizu M, Tanabe S: Cell wall fraction of Enterococcus hirae ameliorates TNF-alpha-induced barrier impairment in the human epithelial tight junction. LettApp/Microbiol 2008, 46:469-476.

51. Korn T, Bettelli E, Oukka M, Kuchroo VK: IL-17 and Th17 Cells. Annu Rev Immunol 2009, 27:485-517.

52. Billiau A, Heremans H, Vandekerckhove F, Dijkmans R, Sobis H, Meulepas E, et al: Enhancement of experimental allergic encephalomyelitis in mice by antibodies against IFN-gamma. J Immunol 1988, 140:1506-1510.

53. Sheikh SZ, Matsuoka K, Kobayashi T, Li F, Rubinas T, Plevy SE: Cutting edge: IFN-gamma is a negative regulator of IL-23 in murine macrophages and experimental colitis. J Immunol 2010, 184:4069-4073.

54. Manoury-Schwartz B, Chiocchia G, Bessis N, Abehsira-Amar O, Batteux F, Muller $S$, et al: High susceptibility to collagen-induced arthritis in mice lacking IFN-gamma receptors. J Immunol 1997, 158:5501-5506.

55. Dinges MM, Schlievert PM: Role of T cells and gamma interferon during induction of hypersensitivity to lipopolysaccharide by toxic shock syndrome toxin 1 in mice. Infect Immun 2001, 69:1256-1264.

56. Tilahun AY, Holz M, Wu TT, David CS, Rajagopalan G: Interferon gammadependent intestinal pathology contributes to the lethality in bacterial superantigen-induced toxic shock syndrome. PLoS One 2011, 6:e16764.

57. Konstantinov SR, Smidt H, de Vos WM, Bruijns SC, Singh SK, Valence F, et al: $S$ layer protein $\mathrm{A}$ of Lactobacillus acidophilus NCFM regulates immature dendritic cell and T cell functions. Proc Nat/AcadSci USA 2008, 105:19474-19479.

58. Dieleman LA, Palmen MJ, Akol H, Bloemena E, Pena AS, Meuwissen SG, et al: Chronic experimental colitis induced by dextran sulphate sodium (DSS) is characterized by Th1 and Th2 cytokines. Clin Exp Immunol 1998, 114:385-391.

59. Wirtz S, Neufert C, Weigmann B, Neurath MF: Chemically induced mouse models of intestinal inflammation. Nat Protoc 2007, 2:541-546.

doi:10.1186/1476-9255-9-7

Cite this article as: Zadeh et al:: Induction of intestinal pro-inflammatory immune responses by lipoteichoic acid. Journal of Inflammation 2012 9:7.

\section{Submit your next manuscript to BioMed Central and take full advantage of:}

- Convenient online submission

- Thorough peer review

- No space constraints or color figure charges

- Immediate publication on acceptance

- Inclusion in PubMed, CAS, Scopus and Google Scholar

- Research which is freely available for redistribution

Submit your manuscript at www.biomedcentral.com/submit
Biomed Central 